\title{
Practice Teaching System and Ability Cultivation of Computer Network
}

\author{
She Wang \\ Wuhan city polytechnic, Wuhan, Hubei, 430064
}

Keywords: Computer; Network Practice Teaching; Cultivation

\begin{abstract}
With the development and advancement of society and economy in our country, our national science and technology has been improved continuously. Since 21st century, informatization has been widespread into every aspect of social life and network application technology has also been more widespread. In order to strengthen practice abilities for students and improve the efficiency of network practice teaching system of computer, higher requirements will be met for professional knowledge and practice abilities of relevant network talents, not only just for laying firm and professional foundation but also for lots of related practice experience. So, establishment of network practice teaching system of computer must be promoted to cultivate students' abilities gradually.
\end{abstract}

With the rapid development of modern information technology, communication technology, database technology, network technology, digital library and computer technology, and the extensive application of database management systems, the speed of data dissemination and accumulation has increased, and the amount of data stored in databases has increased dramatically. All enterprises and institutions have also established their own information management systems and accumulated a large amount of data. Schools are no exception. In most schools, information management has been implemented. E-government systems, educational management systems, teacher information management systems, scientific research information management systems, and teaching evaluation systems have been widely used in universities and have also accumulated a large amount of data. But when we are delighted with extremely detailed data, we also find that new data processing and refining technologies are very scarce.

\section{The current situation of computer network practice teaching}

Traditional database systems can only store, update, and query data, and the amount of information obtained in this way is only a small part of the information contained in the entire database. The school only uses the data to provide information for inquiries and as a basis for awards and evaluations. There is no higher-level analysis and mining of important information hidden behind these data, to find out the relevance and classification of data, and to describe the overall characteristics of the data and predict its development trend. This can make better use of this data to provide decision support for teaching management. It can be seen that decision makers lack the tools to extract knowledge and information from the data. Usually the decision-making comes from the intuition and experience of the decision makers. Faced with the huge amount of data resources, people urgently need powerful tools to find useful information in the data. Data mining technology was created and developed in the context of this demand.

Science and technology gained changing development as times progresses. Because of old practice teaching contents and backward basic knowledge, it is hard for traditional computer network practice teaching to keep pace with the current teaching mode. The reason why students fail to grasp the latest knowledge about computer network technology is that many universities have been adopting traditional teaching mode. So, this is alien from times development.

At present, many universities often attach more importance to theories than practices for curriculums arrangement, which leads most teachers pay much attention to the degree of students' theorical knowledge mastery on computer and ignore cultivating the abilities of practices for 
computer. This cannot meet requirements on talents from modern companies and it is difficult to keep pace with the development of companies.

In light of restrictions on computer network practice teaching curriculums, many universities released low demand for practices, which results in few practice experiences and the students fail to find and solve the problems on time. Because of weak practice abilities that can't satisfy the related employment requirements from companies, it is hard for students to seek for suitable jobs that match their specialties, which causes great employment pressure.

To a certain degree, the employment rate is related with the prestige universities have. The level of practice abilities is closely connected with students' qualities and employment rate. If students lacking practice abilities interns at a company, this will leave bad impression about universities in the companies. The existence of objective information will affect the college aspirations of high school graduates and make colleges facing greater enrollment pressure.

\section{Establishment of relevant systems for computer network practice teaching curriculums}

Designing computer network practice teaching curriculums can improve students' practice abilities. By compulsory courses and optional courses, mastery on basic knowledge and computer learning interest cultivation can be fulfilled. Therefore, schools can enhance students' ability to master basic knowledge step by step by setting up the most basic computer courses, and set up relevant computer elective courses to develop students' practical ability continuously.

Firstly, website design abilities should be improved with one term's basic network curriculums related to computer to cultivate students' network configuration abilities and design abilities of LAN. Secondly, students should master the most basic program designing abilities by computer network curriculums. Thirdly, starting curriculums related to computer safety to promote students' professional abilities and development. Fourth, leading students to obtain professional internships by various means according to the situation of each student after mastering the most basic computer network theorical knowledge to help them to accumulate rich practical experience and improve their practical ability to lay a good foundation for future employment continuously. Fifth, teachers should give some professional guidance to students and lead students to accomplish graduate design relying on their own abilities, as well as offer help according to the situation.

Required by the development and advancement of economy and times, along with the pace of science and technology, designing computer network curriculums must meet the needs of talents in the form of society, and based on the situation of students themselves, applying certain methods to innovate computer network practice teaching continuously.

Firstly, students' practice abilities should be cultivated by building necessary network presence modes. Teachers show the real network in network curriculums and use online method to make students experience what they have grasped in the most intuitional way. For instance, teachers can provide some pages for accessing and can learn relevant ways when teaching web design. Additionally, students should be popularized with study orders and tools to help them use tools to browse websites they are interested in. Students find data and information they need to improve the design abilities of network practice by detailed analysis continuously.

Secondly, a certain topic is designed to improve students' network practice abilities. Under the premise of ensuring students' mastery of basic professional knowledge, starting a topic related to network and guiding students to find information by themselves. Their hands-on ability should be strengthened while the related design of network topics is completed. Teachers can judge whether the students' self-practice ability is improved or not by the related presentation of students in the classroom.

Thirdly, designing network teaching in the reality is of great help to improve students' hands-on abilities. Network analysis can be carried out on the basis of helping students to finish the network design. Then the Network is applied and the mode is evaluated objectively.

Fourthly, universities should update the teaching content and introduce the teaching mode from companies into it. With the continuous maturity of data mining technology and the continuous expansion of application fields, some scholars have also applied association rules to the teaching 
management of schools, and have achieved some results. Some domestic scholars use the improved algorithms based on clustering-based association rules to mine student achievement data. He used cluster analysis as a pre-processing of the association rule algorithm, which greatly reduced the scope of the data set in the analysis of association rules, thereby improving the mining efficiency. There are also literatures that apply unimproved association rules to teaching evaluation data analysis, but the efficiency of mining is low. There are also Apriori algorithms that are optimized using pruning techniques to analyze university teacher information and improve the efficiency of the algorithm to a certain extent. However, a large number of rules generated by mining are not filtered by metrics to obtain more effective and reasonable rules. This article will address traditional metrics-confidence frameworks, as well as metrics such as validity and relevance. The measure of influence degree based on the T-test idea is proposed and applied to the multimedia teaching evaluation data analysis. At present, the teaching evaluation data analysis system based on data mining technology is basically a standalone version, since the current teaching evaluation is based on the network. Therefore, this paper develops a multimedia teaching evaluation data analysis system based on the J2EE framework for network requirements. This is of great significance to providing association guides for teaching decision makers through association mining.

Fifthly, universities should pay attention to cultivate term abilities and keep improving the teaching practice. Teachers should focus on the scene teaching and impart basic, theorical and systematic knowledge to students via live showcase to digest and form reasonable knowledge system. Besides, students are reasonably divided into several groups by designing scientific experimental projects. After a clear division of labor, the groups accomplish their own tasks, which helps to train students' organizational skills and hands-on ability, and to cultivate students' solidarity and cooperation skills. This is also beneficial for their ability to analyze and summarize.

Sixth, relevant training mechanisms should be introduced from companies to improve the cultivation of computer network practice ability of teachers and students. Universities should establish sound partnership with companies and send teachers to learn at a company in an indefinite time. Teachers will obtain relevant certificates based on their assessment results. For teachers, professional abilities will be enhanced to be proficient of teaching knowledge by professional training. Meanwhile, they can guide and help students to solve problems faced by them. Moreover, universities can hire professional technical personnel and project directors with rich practice experience as a consultant, which is of great help to start teaching tasks for universities. On one hand, this can improve teachers' practice abilities efficiently and make them impart knowledge better. On the other hand, this can give students the opportunity to contact teachers outside the classroom, feel the teaching style from different teachers, make up for the lack of their theoretical knowledge and practical ability, and understand the development needs of modern enterprises in advance, so as to help them find the method of learning hard and achieve better development.

Seventh, universities can assign students to have internships in companies to boost cooperation with it. For students, universities send students who will graduate to some companies related to computer network technology, which can help students build a relationship with companies before employment. After learning and development at a company, integrating theories with practices is of great help to master the most advanced science and technology, cultivate ability to deal with emergence and seek for a good job. For companies, they can train students' scientific knowledge by observing their routine and judge whether students master enough professional theorical knowledge and have practice abilities via regular assessment. According to the results, students should be offered professional and directed cultivation to improve their practice ability, which can help companies train professional technical personnel and promote sustainable development for companies.

\section{Conclusion}

Based on the situation of computer network teaching, the strategy of improving computer network practice teaching is proposed in the aspect of the establishment in necessary network presence mode to cultivate students' practice abilities, design network teaching in the reality, 
updating teaching contents on time, introducing modern companies' teaching modes into network teaching, paying attention to cultivate term abilities, improving teaching practice, applying relevant training mechanisms from companies as well as enhancing cooperation with companies and assigning students to complete internship in companies.

\section{Acknowledgment}

Foundation Project: The 2018 Schoollevel Ph.D. Project of Wuhan City Polytechnic, "The impact of 'Made in China 2025' on the Curriculum System Structure and Reform Practice of Vocational College Electronic Information Professional Group", Project Number: 2018whcvcS13

\section{References}

[1] Zhang Xiaoming, Chen Ming, Du Tiancang, et al. Computer Network Practice Teaching System and Ability Cultivation [J]. Laboratory Research and Exploration, 2013(10).

[2] Li Gang. Computer Network Practice Teaching System and Ability Cultivation [J]. Wireless Interconnect Technology, 2014(8).

[3] Zhang Yuling. Shallow Thinking on Computer Network Practice Teaching and Ability Cultivation [J]. Caizhi, 2015(32). 